\title{
OS 170 ANOS DOS CURSOS JURÍDICOS NO BRASIL E AS ACTAS DA CONGREGAÇÃO DOS LENTES DA ACADEMIA DE DIREITO DE SÃO PAULO
}

\author{
Álvaro Villaça Azevedo \\ Diretor da Faculdade de Direito da Universidade de São Paulo
}

As Actas da Congregação de Lentes da Academia da Universidade de Direito de São Paulo, organizadas pelo Diretor desta Faculdade, professor dr. Álvaro Villaça Azevedo, com a colaboração do professor e pesquisador Aurélio Wander Bastos e reproduzidas pela Xerox do Brasil com a decisiva colaboração do presidente da Xerox do Brasil, dr. Carlos Salles, e do seu Diretor, Heitor Chagas, em quatro volumes, contêm alguns dos mais preciosos documentos da história da Faculdade, do ensino jurídico, da Província de São Paulo e do Brasil-Império.

O primeiro volume referente ao período de reuniões compreendido entre 1874/1885 foi lançado no Salão Nobre da Faculdade de Direito de São Paulo no dia 11 de outubro de 1996, sob a presidência do Diretor desta Faculdade, com a presença do ministro do STF Sydney Sanches, do, à época, secretário de Direito Econômico do Ministério da Justiça, Aurélio Wander Bastos, que fez uma elucidativa exposição sobre a história e a evolução do ensino jurídico no Brasil, onde destacou o especial papel desempenhado na definição dos currículos e programas pela antiga Congregação dos Lentes. Naquela mesma ocasião, como presidente da Sessão solene da Congregação, destacou o Diretor os esforços para a realização da coletânea, assim como a sua importância para a recuperação das principais questões acadêmicas e administrativas que afetaram a implantação da Academia de Direito em São Paulo.

Nesse volume das Actas de 1874 a 1885, apresentam-se opiniões de brasileiros ilustres como Vicente Pires da Mota, tradicional Diretor por muitos e consecutivos anos da Academia de São Paulo, Martin Francisco Ribeiro de Andrade, José Bonifácio Ribeiro de Andrade e Silva, Antonio Carlos Ribeiro de Andrada Machado e Silva, nomes ilustres vinculados à formação do estado nacional brasileiro como José Maria de Sá e Benevides, protagonista de uma contenda pública com Rui Barbosa, patrono dos advogados, sobre o ensino do Direito Romano, sua conveniência e necessidade acadêmica. Da mesma forma, neste volume, encontra-se o material referente a concurso de lentes, horário de aulas, programas de disciplinas 
e todos os temas que permeiam o cotidiano da vida acadêmica, inclusive sobre a frequêencia permitida e simultânea à Academia de São Paulo e à Academia de Recife (transferida de Olinda em 1854), realidade acadêmica do importante fenômeno político-institucional do Império: a circulação das elites.

O segundo volume das Actas, referente às anotações das reuniões realizadas entre os anos de 1885 a 1897, foi divulgado publicamente em maio deste ano, no Saguão Negro do Ministério da Justiça, em solenidade presidida pelo então ministro da Justiça, Nelson Jobim, e com as presenças do Diretor desta Faculdade, do vice-presidente da República, Marco Maciel, e dos presidentes do Supremo Tribunal Federal, Sepúlveda Pertence, e do Superior Tribunal de Justiça, Romildo Bueno de Souza.

Nessa ocasião, usando da palavra o vice-presidente da República, Marco Maciel, ressaltou a importância da Academia de Direito de Olinda, também fundada em 1827, instalada em 15 de maio de 1828 no Mosteiro de São Bento, onde se destacaram lentes e professores da maior envergadura e importância para a Província de Pernambuco. Depois de ressaltar a importância da pesquisa realizada pelo professor Aurélio Wander Bastos, destacou o significado histórico de antigos diretores da Academia de Olinda, especialmente o seu Diretor-fundador Pedro de Araújo Lima, depois Marquês de Olinda, que tomou posse em $1^{\circ}$ de março de 1828 e teve como seu Diretor-substituto Lourenço José Ribeiro. Lembrou também o vicepresidente da República os laços de associação entre a Academia de São Paulo e a Academia de Olinda, muito especialmente relevando o papel do Diretor Antonio Peregrino Maciel Monteiro, Barão de Itamaracá, que tomou posse em 1839 sem que se esquecesse do período de interinidade (1839/40) do Bispo Tomás Noronha e da longa gestão do Frade Miguel do Sacramento Lopes Gama (1835/47), além do seu sucessor, Bernardo José da Gama (que tomou posse em 1850), Visconde de Goiana.

Lembrou, ainda, que também tiveram significativa importância para a consolidação do ensino jurídico no Brasil os professores da Academia Co-Irmã da Academia de São Paulo, Leôncio Ribeiro (vice-diretor), Lourenço José Ribeiro (professor de Direito Constitucional), Manuel José da Silva Porto (professor de Direito Eclesiástico), José de Moura Magalhães (professor de Direito Constitucional), Pedro Autran da Mata e Albuquerque e Zacarias de Góes e Vasconcellos, João Lins Cansanção do Sinimbu e José Tomás Nabuco de Araújo.

Em seguida, na mesma sessão realizada no Ministério da Justiça, usando da palavra o ministro Nelson Jobim demonstrou a importância dos Cursos 
Jurídicos, muito especialmente da Faculdade de Direito de São Paulo, no processo de formação e desenvolvimento do pensamento jurídico brasileiro, assim como na consolidação das instituições jurídicas nacionais. O pronunciamento do Diretor desta Faculdade, no encerramento da solenidade, destacou o conferido genérico dos atos e muito especialmente as anotações sobre o ensino de Direito Romano, cujo berço de fortalecimento estava na Academia de Direito de São Paulo.

Nesse volume referente aos anos de 1885/97, inúmeras são as opiniões dos professores sobre as questões da crise imperial que já se aproximava: o problema da Guerra do Paraguai, o problema da escravatura, questão republicana e até questões referentes à monarquia federativa e as sucessivas leis de ensino. Dentre os professores desse período (os últimos anos do Império), destacam-se: Brasílio Machado, Américo Brasiliense, Antônio Carlos Ribeiro de Andrada, João Mendes de Almeida Jr., Pedro Lessa, autor da clássica obra sobre O Poder Judiciário no Brasil, André Fleuri que por muitos anos foi Diretor da Academia, Carlos Leôncio de Carvalho, autor da mais polêmica Lei de Ensino da História Educacional Brasileira: A Lei do Ensino Livre, que permitiu a abertura de novas escolas de Direito alternativo às duas de São Paulo e Recife (para onde em 1854 se transferiu a Academia de Olinda), inclusive, a Faculdade Livre de Direito e a Faculdade Livre de Ciências Jurídicas no Rio de Janeiro. Nesse volume estão também as proposições do Barão de Ramalho, primeiro Diretor republicano, e antigo lente imperial, como que demonstrando os vínculos de continuidade de ensino, apesar da ruptura institucional profunda.

O terceiro volume das Actas, referente ao período de 1897 a 1906, foi lançado no Plenário do Conselho Federal da Ordem dos Advogados do Brasil no dia 19 de agosto de 1997, em solenidade presidida pelo seu presidente Ernani Uchoa Lima, quando estiveram presentes, além do Diretor desta Faculdade, expressivas autoridades da República dentre elas: o presidente da Câmara dos Deputados, Michel Temer, o ministro da Justiça, Íris Resende, o ministro do STF, Sepúlveda Pertence, o presidente do Tribunal de Contas da União, Marcos Vilaça e o convidado especial, organizador da obra, Aurélio Wander Bastos.

No seu pronunciamento inaugural, o presidente do Conselho Federal da OAB, Ernani Uchoa Lima, observou que "Estas Atas, trazidas a público no ano em que comemoramos os 170 anos de criação dos Cursos Juridicos no Brasil e o Dia dos Advogados são a demonstração lídima dos compromissos dos nossos advogados brasileiros com a sobrevivência das instituições políticus tradicionais e com o seu engajamento na história brasileira presente. Os advogados brasileiros 
estão, e sempre estiveram, engajados e empenhados no processo de mudanças políticas e institucionais, resguardando os ideais de justiça e liberdade, respeitando as nossas tradições democráticas: tradições que sempre foram um paradigma de nossos Cursos Jurídicos e nosso Poder Judiciário(...)"

Nessas Actas, podem identificar-se os principais atos praticados pela Congregação dos Lentes da Academia de São Paulo, mas, muito especialmente, permitem identificar não apenas a trajetória e o posicionamento intelectual de importantes personalidades políticas da História imperial, mas também as opiniões de nossos antigos lentes de Direito sobre as questões centrais da vida política, institucional e acadêmica. Não há como desconhecer que esses documentos são uma verdadeira preciosidade para a História brasileira, e para os Cursos Jurídicos no Brasil.

Finalmente, a solenidade final, realizada na Sala da Congregação da Faculdade, em Sessão presidida por seu Diretor, com a presença ilustre dos senhores professores e do professor Aurélio Wander Bastos, que permitiu transformar esses eventos nos mais importantes atos comemorativos dos 170 anos dos Cursos Jurídicos no Brasil, o lançamento do primeiro conjunto da coletânea de Actas, referente ao período de 1837 a 1855 , sensivelmente danificadas pela ação do tempo e pelo incêndio que afetou os arquivos da Faculdade no dia 16 de fevereiro de 1880 e que destruiu os volumes antecedentes, mas que ainda permitem identificar a participação do nosso primeiro Diretor da Academia de São Paulo, Marechal Rendon.

Esse período de reuniões basicamente esteve concentrado na discussão do regulamento da Escola e de seu regime de funcionamento, bem como na elaboração horária. A ação do próprio tempo, assim como as modelações taquigráficas das anotações exigirão um tempo mais longo para melhor identificação desse material, mas com certeza permitem afirmar que aqui, nessas Actas, estão preciosas opiniões sobre algumas das mais importantes instituições jurídicas e políticas brasileiras. Não há como desconhecer que muitas das instituições brasileiras os nossos modelos de ensinar são aprender -, nasceram aqui e dessa referência histórica continua como fundamento a história do ensino jurídico no Brasil.

Destaque-se que grande parte das informações históricas, aqui prestadas, fundamentou-se na pesquisa do professor Aurélio Wander Bastos. 